\title{
EVALUASI USAHA PENGGILINGAN PADI SUMBER HIDUP DI DESA MARINDI KECAMATAN HARUAI KABUPATEN TABALONG
}

\author{
Gusti Marliani \\ Fakultas Ekonomi Universitas Achmad Yani Banjarmasin \\ Jl. A.Yani KM. 5,5 Komplek Stadion Lambung Mangkurat Banjarmasin, Indonesia
}

\begin{abstract}
The purpose of this research is to determine the production cost, the eligibility and sensitivity of "Sumber Hidup" rice milling business in Marindi village, sub-district of Haruai, Tabalong regency. This research uses quantitative analysis methods. The data collecting has been done in April to May 2015. The quatitative analysis methods use invesment criteria analysing with:, Net Present Value (NPV), Internal Rate of Return (IRR), Net Benefit Cost Ratio (Net B/C), and business sensitivity. Based on the research, the eligibility of business study conclude that "Sumber hidup" rise milling business is worth to be carried on as long as the range of production cost is $10 \%$ to $40 \%$. But if the production cost reach more than $50 \%$ of the whole cost, the business is not worth to be carried on.
\end{abstract}

Keywords: rice milling, eligibility and sensitivity of the business.

DOI : http://dx.doi.org/10.21067/jem.v12i2.1195

Diterima : April 2016; Direvisi: Mei 2016; Diterima : Juni 2016

\section{PENDAHULUAN}

Indonesia adalah negara agraris yang sebagian besar penduduknya terdiri dari petani sehingga sektor pertanian memegang peranan penting. Sektor pertanian sebagai sumber kehidupan bagi sebagian besar penduduk terutama bagi mereka yang memiliki mata pencaharian utama sebagai petani. Selain itu sektor pertanian, adalah salah satu hal penting yang harus diperhatikan sebagai penyedia pangan bagi masyarakat. Peningkatan produksi yang harus seimbang dengan laju pertumbuhan penduduk dapat dicapai melalui peningkatan pengelolaan usaha tani secara intensif. Oleh karena itu, pengetahuan untuk peningkatan usaha tani dibutuhkan untuk meningkatkan pro-

* Corresponding Author.

E-mail: marlianigusti@yahoo.co.id duktifitas dan pendapatan sehingga

kesejahteraan petani dapat meningkat.

Kesejahteraan petani juga ditentukan oleh luas lahan, luas panen dan produksi tanaman padi pada suatu wilayah.

Studi pendahuluan yang dilakukan oleh penulis di Balai Penyuluhan Pertanian Kecamatan Kembang Kuning tentang perkembangan luas tanam, luas panen dan produksi tanaman padi di Kecamatan Haruai Kabupaten Tabalong selama 5 tahun terakhir (2010-2014), Berdasarkan tabel 1 dapat diketahui , pada tahun 2011 hasil produksi padi sebesar 8.275,46 ton, pada tahun 2012 produksi padi di Kecamatan Haruai mengalami penurunan menjadi 4.212.75 ton, karena akibat terjadinya banjir pada saat tanaman padi mulai mengurai, sehingga terjadi gagal panen. Pada tahun 2013-2014 hasil produksi padi 
mengalami peningkatan menjadi $8.771,83$ ton dan pada tahun 2015 meningkat lagi menjadi $10.154,10$ ton.Salah satu kegiatan pascapanen, khususnya pascapanen padi yaitu penggilingan padi menjadi beras. Beras merupakan salah satu makanan pokok bangsa Indonesia. Oleh karena itu, perhatian akan beras atau tanaman padi tidak ada henti-hentinya. Perjalanan bangsa Indonesia dalam pengadaan beras pun berliku-liku yang pada akhirnya dapat berswasembada beras pada tahun 1984 .

Tabel 1.

Perkembangan Luas Tanam, Panen, dan Produksi

Tanaman Pangan di Kecamatan Haruai tahun 20102014

\begin{tabular}{ccccc}
\hline No & Tahun & $\begin{array}{c}\text { Tanam } \\
\text { (HA) }\end{array}$ & $\begin{array}{c}\text { Panen } \\
\text { (Ha) }\end{array}$ & $\begin{array}{c}\text { Produksi } \\
\text { (ton) }\end{array}$ \\
\hline 1 & 2010 & 1847,2 & 1847,2 & $8.275,46$ \\
2 & 2011 & 1847,2 & 1027,5 & $4.212,75$ \\
3 & 2012 & 1846,7 & 1846,7 & $8.326,36$ \\
4 & 2013 & 1846,5 & 1846,5 & $8.771,83$ \\
5 & 2014 & 1846,2 & 1846,2 & $10.154,10$ \\
\hline \multicolumn{5}{l}{ Sumber : BPP Kec. Kembang Kuning 2015 }
\end{tabular}

Penggilingan gabah menjadi beras merupakan salah satu rangkaian utama penanganan pascapanen. Teknologi penggilingan sangat menentukan kuantitas dan kualitas beras yang dihasilkan. Perbandingan antara beras giling dan kehilangan hasil serta mutu beras hasil penggilingan tergantung pada tingkat kematangan biji saat dipanen. Satu diantara sarana yang diperlukan dalam mengolah hasil panen adalah dengan melaksanakan usaha penggilingan padi.

Usaha jasa penggilingan padi tidak terlalu rumit untuk dijalankan, maka risiko yang ada juga relatif kecil dan mudah ditanggulangi. Risiko terbesar adalah sedikitnya pengguna atau rendahnya produktivitas padi per hektar, risiko lainnya adalah kerusakan mesin-mesin penggilingan padi sehingga menyebabkan penurunan kapasitas giling dan mutu hasil gilingan. Selain itu kenaikan biaya operasional juga dapat mempengaruhi kelangsungan usaha jasa penggilingan padi. Variabel biaya terbesar dalam operasional usaha jasa penggilingan padi adalah bahan bakar minyak dan penggantian rubber roll.

Penggilingan padi kini telah mengalami perkembangan yang cukup pesat. Kebayakan para petani di Desa Marindi, Desa Wirang, dan Desa Bongkan, Desa Saradang bahkan sebagian para petani yang tinggal di kecamatan lain juga ada yang menggunakan jasa penggilingan padi Sumber Hidup untuk menggiling padinya. Untuk hasil produksi penggilingan padi " Sumber Hidup" dapat di lihat pada tabel berikut:

Tabel 2.

Hasil Produksi Penggilingan Padi "Sumber Hidup" 2010-2014

\begin{tabular}{cccccc}
\hline \multirow{2}{*}{ No } & \multirow{2}{*}{ Tahun } & \multicolumn{2}{c}{ Gabah Digiling } & \multirow{2}{\text{Harga}}{ Pendapatan } \\
\cline { 3 - 5 } & & Ton & $\mathrm{Kg}$ & $\mathrm{Rp} / \mathrm{kg}$ & Penc \\
\hline 1 & 2010 & 192 & 192.000 & 250 & 48.000 .000 \\
2 & 2011 & 171,4 & 171.429 & 350 & 60.000 .150 \\
3 & 2012 & 210 & 210.000 & 500 & 105.000 .000 \\
4 & 2013 & 204 & 204.000 & 500 & 102.000 .000 \\
5 & 2014 & 212 & 212.000 & 600 & 127.200 .000 \\
\hline
\end{tabular}

Sumber : Hasil Pengolahan Data Primer, 2015

Dari tabel 2 diketahui usaha penggilingan padi "Sumber Hidup" yang berada di Desa Marindi Kecamatan Haruai Kabupaten Tabalong mempunyai jumlah gabah yang digiling dalam jumlah yang fluktuatif, dari tahun 2010 ke tahun 2011 mengalami penurunan dan pada tahun 2012 hasil produksi penggilingan padi meningkat menjadi 210 ton dan harga upah juga meningkat menjadi Rp. $500,-/ \mathrm{kg}$ Kemudian ditahun 2013 kembali terjadi penurunan menjadi 204 ton, pada tahun 2014 gabah yang digiling meningkat lagi menjadi 212 ton dan harga naik menjadi $\mathrm{Rp}$. $600,-/ \mathrm{Kg}$. Kenaikan harga upah penggilingan padi terjadi karena menyesuaikan dengan biaya pemeliharaan mesin dan tenaga kerja.

Berdasarkan uraian diatas maka perlu perencanaan dan perhitungan yang tepat melalui analisis kelayakan dan tingkat sensitivitas usaha. Hasil analisis yang diperoleh selanjutnya dijadikan sebagai bahan masukan bagi pemerintah daerah dan seluruh stakeholder 
terkait guna pengembangan agribisnis pertanian. Untuk itu maka perlu dilakukan kajian penelitian tentang analisis kelayakan dan sensitivitas usaha penggilingan padi "Sumber Hidup" di Desa Marindi Kecamatan Haruai Kabupaten Tabalong.

Berdasarkan uraian pada latar belakang maka dapat dirumuskan beberapa masalah sebagai berikut: (1). Bagaimana tingkat kelayakan usaha penggilingan padi "Sumber Hidup" di Desa Marindi, Kecamatan Haruai Kabupaten Tabalong?, (2). Bagaimana tingkat sensitivitas usaha penggilingan padi "Sumber Hidup" di Desa Marindi, Kecamatan Haruai Kabupaten Tabalong?

\section{TINJAUAN PUSTAKA}

Setiap usaha didirikan dengan tujuan untuk mendapatkan keuntungan,tetapi tidak semua usaha selalu mendatangkan keuntungan adakalanya usaha tersebut juga mengalami kerugian,karena setiap usaha selalu menghadapi suatu resiko yang tidak diinginkan yaitu rugi. Untuk menghindari resiko kerugian itulah maka diperlukan suatu penjajakan atau perhitungan melalui suatu analisa,yaitu analisis studi kelayakan bisnis,dengan demikian dapat dilihat apakah usaha tersebut layak dijalankan/ diteruskan atau tidak.

Menurut Kasmir dan Jakfar (2003) Studi kelayakan Bisnis adalah suatu kegiatan yang mempelajari secara mendalam tentang suatu kegiatan atau usaha atau bisnis yang akan dijalankan dalam rangka menetukan layak atau tidaknya usaha tersebut dijalankan. Untuk mengetahui layak atau tidaknya suatu usaha perlu dilakukan suatu analisis yaitu analisis finansial.Untuk menentukan kelayakan usaha dalam anlisis finansialdigunakan alat ukur atau kriteria yang disebut dengan kriteria investasi.

Menurut Abdul Choliq, H.R A Rivai Wirasasmita dan Sumarna Hasan (1999); Kriteria investasi merupakan alat ukur yang menntukan apakah suatu proyek layak atau tidak untuk dilaksanakan. Selanjutnya masih menurut Abdul Choliq, H.R A Rivai Wirasasmita dan Sumarna Hasanbahwa ada 5 (lima) Kriteria Investasi yang digunakan dalam Studi Kelayakan Yaitu, Net Present Value
(NPV), Net Benefit Cost Ratio (Net B/C), Gross Benefit Ratio (Gross B/C), Internal Rate of Return (IRR), Profitability Ratio (PR)

Pernyataan tentang 5 (lima) Kriteria Investasi yang digunakan untuk menilai kelayakan usaha tersebut juga didukung oleh pernyataan H.M Yacob Ibrahim (2009): "Kriteria Investasi yang dugunakan dalam analisis adalah : Net Present Value (NPV), Internal Rate of Return (IRR), Net Benefit Cist Ratio (Net B/C), Gross Benefit Ratio (Gross B/C), Profitability Ratio (PR).

Menurut penelitian Pradhana (2011), Analisis Biaya dan Kelayakan Usaha Penggilingan Padi di Desa Cihideung Ilir, Kecamatan Ciampea, Kabupaten Bogor dari hasil analisis sensitivitas diketahui bahwa kenaikan harga bahan bakar solar sebesar $10 \%$ dari harga normal dan diikuti dengan kenaikan upah hingga 40\%, maka membuat usaha penggilingan padi menjadi tidak layak. Kenaikan harga bahan bakar solar sebesar 20\% dan $30 \%$ dari harga normal dengan diikuti kenaikan upah hingga 30\%, maka membuat usaha penggilingan padi menjadi tidak layak. Analisis sensitivitas untuk penurunan jumlah giling tahunan hingga 20\% akan menyebabkan usaha penggilingan padi ini menjadi tidak layak untuk dijalankan.

Menurut Idris (2013), dalam penelitian Analisis Kelayakan Usaha Penggilingan Padi “ Tiga Bersaudara" di Desa Bungin Kecamatan Paringin Selatan Kabupaten Balangan. Analisis kelayakan finansial dapat dilihat dari nilai NPV sebesar Rp. 10.736.475,- IRR yang dihasilkan adalah $6,86 \%$, Net B/C sebesar 1,27 dan titik impasnya berada pada jumlah produksi sebesar 13.394.203 kg dan Rp. 6.060.328,. Dengan demikian kelayakan Usaha Penggilingan padi "Tiga Bersaudara" di Desa Bungin Kecamatan Paringin Selatan Kabupaten Balangan dapat dikatan layak untuk tetap dikembangkan.

Sapmaya Wulan (2010), dalam penelitian yang berjudul Studi Kelayakan Usaha Pencucian Mobil Otomatis Pada Perusahaan Auto Car Wash di Bandar Lampung,dari hasil kriteria investasi diperoleh $\mathrm{NPV}=215.734 .000$ berarti NPV $>0$, Net B/C $=1,22(\mathrm{Net} \mathrm{B} / \mathrm{C}>0), \mathrm{IRR}=22,96 \%$ dengan 
tingkat bunga $15 \%$ berarti IRR > tingkat bunga, dengan demikian usaha layak untuk dilaksanakan.

\section{METODE}

Penelitian ini dilaksnakan pada Usaha Penggilingan Padi “ Sumber Hidup” yang berada di Desa Marindi Kecamatan Haruai Kabupaten Tabalong, waktu penelitian dilaksanakan mulai bulan Juni 2015 sampai bulan Desember 2015. Variabel yang digunakan berhubungan dengan variabel biaya dan variabel operasional usaha mesin pada penggilingan padi, antara lain jenis penggilingan yang digunakan dan komponenkomponennya, biaya-biaya yang dikeluarkan (biaya tetap dan biaya tidak tetap), rata-rata pemakaian bahan bakar per jam, rata-rata jumlah gabah yang digiling per hari dan sebagainya. Penelitian ini secara keselurahan digunakan untuk mengkaji dan menganalisis biaya dan kelayakan usaha pengilingan padi, data yang digunakan adalah data sekunder yang diperoleh dari laporan keuangan Usaha Penggilingan Padi Sumber Hidup dan instansiinstansi yang terkait serta studi pustaka dari berbagai media yang berhubungan dengan penelitian ini.

\section{Analisis Data}

Analisis data untuk mengetahui tujuan pertama yakni analisis kelayakan usaha pengilingan padi "Sumber Hidup" terlebih dahulu di tentukan biaya total, penerimaan dan keuntungan dengan menggunakan rumus :

1) Biaya total:

$$
\begin{aligned}
& \mathrm{TC}=\text { TFC }+ \text { TVC } \\
& \mathrm{TC}=\text { Total Cost (total biaya) } \\
& \mathrm{TFC}=\text { Total Fixed Cost (total biaya tetap) } \\
& \mathrm{TVC}=\text { Total Variable Cost (biaya tidak } \\
& \text { tetap) }
\end{aligned}
$$

2) Penerimaan :

$$
\begin{aligned}
& \mathrm{TR}=\mathrm{Y} . \text { Py } \\
& \mathrm{TR}=\text { Total Revenue (total penerimaan) } \\
& \mathrm{Y}=\text { Produksi yang diperoleh } \\
& \mathrm{Py}=\text { Harga } \mathrm{Y}
\end{aligned}
$$

3) Keuntungan :

$\mathrm{P}=\mathrm{TR}-\mathrm{TC}$

$\mathrm{P}=$ Keuntungan

$\mathrm{TR}=$ Total Revenue (total penerimaan)

$\mathrm{TC}=$ Total Cost (total biaya)

\section{Net Present Value (NPV)}

$\mathrm{NPV}=\sum_{\mathrm{i}=\mathbf{1}}^{\mathrm{n}} \mathrm{NB}_{\mathrm{i}}(1+\mathrm{i})^{-\mathrm{n}}$

$$
\begin{aligned}
& \text { NPV }=\text { Net Present Value }(\mathrm{Rp}) \\
& \mathrm{NB}=\text { Net Benefit }=\text { Benefit }- \text { Cost } \\
& \mathrm{n} \quad=\text { Tahun } \\
& \mathrm{i} \quad=\text { Discount factor }
\end{aligned}
$$

Apabila hasil perhitungan net present value lebih besar dari 0 (nol), dikatakan usaha/proyek tersebut feasible (go) untuk dilaksanakan dan jika lebih kecil dari 0 (nol) tidak layak untuk dilaksanakan. Hasil perhitungan net present value sama dengan 0 (nol) ini berarti proyek tersebut berada dalam keadaan break even point (BEP) dimana $\mathrm{TR}=$ TC dalam bentuk presen value, atau dengan kata lain

NPV $>0$ maka usaha layak dijalankan NPV $<0$ maka usaha tidak layak dijalankan.

\section{Internal Rate of Return (IRR)}

IRR akan diperoleh pada saat NPV $=0$. Untuk itu dilakukan coba-cobapada berbagai tingkat bunga untuk mendapatkan NPV mendekati 0 pada tingkat bunga tertentu $\left(i_{1}\right)$ dan NVP mendekati 0 pada tingkat bunga tertentu ( $\left.i_{2}\right)$. Untuk mencari IRR dilakukan interpolasi antara $i_{1}$ yang menghasilkan $\mathrm{NPV}_{1}$ dengan $i_{2}$ yang menghasilkan $\mathrm{NPV}_{2}$ Dalam persamaan dapat dinyatakan sebagai berikut :

$\operatorname{IRR}=\mathbf{i}_{1}+\frac{\mathrm{NPV}_{1}}{\mathrm{NPV}_{1}-\mathrm{NPV}_{2}}\left(\mathbf{i}_{2}-\mathbf{i}_{1}\right)$

Diketahui :

IRR = Internal Rate of Return 
$\mathrm{i}_{1}=$ Tingkat suku bunga yang menghasilkan NPV positif

$\mathrm{i}_{2}=$ Tingkat suku bunga yang menghasilkan NPV negative

$\mathrm{NPV}_{1}=\mathrm{NPV}$ yang bernilai positif

$\mathrm{NPV}_{2}=\mathrm{NPV}$ yang bernilai negative

Proyek dikatakan layak bila IRR lebih dari tingkat suku bunga (i) yang berlaku.

\section{Net Benefit Cost Ratio (Net B/C)}

Perhitungan Net B/C dilakukan untuk melihat berapa kali lipat manfaat akan diperoleh dari biaya yang dikeluarkan.

Net $B / C=\frac{\sum_{i=1}^{n} N_{i}(+)}{\sum_{i=1}^{n} N B_{i}(-)}$

$$
\begin{aligned}
\text { Diketahui } & : \\
\text { NB } & =\text { Net benefit } \\
\mathrm{N} & =\text { Umur Produksi } \\
\mathrm{I} & =\text { Discount factor }
\end{aligned}
$$

Bila Net $\mathrm{B} / \mathrm{C}>1$ proyek dianggap layak, Net $\mathrm{B} / \mathrm{C}=1$ merupakan titik impas dan bila Net B/C < 1 maka proyek dinyatakan tidak layak (Ibrahim, 2009).

\section{Analisis Sensitivitas}

Untuk mengetahui akibat dari perubahan parameter-parameter produksi terhadap perubahan kinerja sistem produksi dalam menghasilkan keuntungan. Melalui simulasi jika terjadi kenaikan biaya variabel akibat kenaikan harga solar maupun kenaikan dari semua unsur biaya variabel keseluruhan dari 10 $\%, 20 \%$, dan seterusnya hingga didapat nilai criteria investasi menjadi tidak layak.

\section{HASIL PENELITIAN}

Analisis Biaya dan Pendapatan Produksi Penggilingan Padi "SumberHidup'

Setiap usaha yang telah beroperasi pasti mengeluarkan sejumlah biaya untuk menjalankannya dan menjual suatu barang atau jasa untuk memperoleh keuntungan termasuk dalam menjalankan usaha pelayanan penggilingan padi. Biaya pada dasarnya adalah nilai dari semua input bagi terselenggaranya kegiatan dan proses produksi usaha sejak awal sampai dengan diperolehnya output atau hasil yang diselenggarakan. Biaya output merupakan biaya investasi yang jumlah modalnya dikeluarkan untuk membuka usaha. Biaya invastasi pada usaha penggilingan padi "Sumber Usaha" di Desa Marindi Kecamatan Haruai Kabupaten Tabalong dapat dilihat pada tabel 4.

Tabel 4.

Biaya Investasi

\begin{tabular}{llrrrrrr}
\hline No & JenisInvestasi & Vol. & $\begin{array}{c}\text { Harga } \\
\text { (Rp/Unit) }\end{array}$ & \multicolumn{1}{c}{$\begin{array}{c}\text { Jumlah } \\
\text { Rp })\end{array}$} & $\begin{array}{c}\text { Umur- } \\
\text { Eko- } \\
\text { nomis }\end{array}$ & $\begin{array}{c}\text { Biaya } \\
\text { Penyu } \\
\text { sutan }\end{array}$ & Nilai Sisa \\
\hline 1 & Bangunan & 1 & 30.000 .000 & 30.000 .000 & 20 & 1.350 .000 & 3.000 .000 \\
2 & Mesin Pemecah Gabah & 1 & 10.000 .000 & 10.000 .000 & 10 & 950.000 & 500.000 \\
3 & MesinPenyosoh & 1 & 10.000 .000 & 10.000 .000 & 10 & 950.000 & 500.000 \\
4 & Tong 1200 Lt & 1 & 1.200 .000 & 1.200 .000 & 10 & 114.000 & 60.000 \\
5 & Timbangan & 1 & 1.500 .000 & 1.500 .000 & 10 & 142.500 & 75.000 \\
6 & Bakul & 10 & 45.000 & 450.000 & 2 & 225.000 & - \\
7 & Drum & 2 & 200.000 & 400.000 & 5 & 72.000 & 40.000 \\
8 & Derigen & 4 & 25.000 & 100.000 & 5 & 18.000 & 10.000 \\
9 & Belik & 1 & 50.000 & 50.000 & 5 & 9.000 & 5.000 \\
10 & Literan & 1 & 20.000 & 20.000 & 5 & 3.600 & 2.000 \\
\hline \multicolumn{2}{r}{} & JUMLAH & & 53.720 .000 & - & 3.834 .100 & - \\
\hline
\end{tabular}

Sumber:Hasil Pengolahan Data , 2015 
Komponen biaya yang dihitung dan dianalisis pada usaha penggilingan padi meliputi biaya tetap (Fixed Cost), biaya variabel (Variabel cost), biaya operasional, penerimaan, keuntungan, kelayakan usaha dengan menggunakan kriteria investasi Net Persent Value (NPV), Internal Rate Of Return (IRR),danNet Benefit Cost Ratio (Net B/C) serta sensitivitas usaha.

\section{Biaya Tetap (Fixed Cost)}

Biaya adalah biaya yang memang harus dikeluarkan, tanpa terikat pada ada atau tidaknya hasil produksi yang diperoleh. Biayabiaya yang termasuk dalam biaya tetap pada usaha penggilingan padi "Sumber Hidup" di Desa Marindi adalah biaya penyusutan dan PBB. Adapun biaya tetap usaha penggilingan padi adalah Rp. 3.846.100,-dimana biaya ini dikeluarkan tiap tahunnya dan diperhitungkan selama 5 tahun.

Tabel 5. Biaya Tetap Usaha

\begin{tabular}{clr}
\hline No & \multicolumn{1}{c}{ JenisBiaya } & \multicolumn{1}{c}{$\begin{array}{l}\text { BiayaTetap } \\
\text { (Rp/Tahun) }\end{array}$} \\
\hline 1 & $\begin{array}{l}\text { Biaya Penyusutan } \\
\text { Pajak Bumi dan Bangunan } \\
\text { (PBB) }\end{array}$ & 3.834 .100 \\
& & 12.000 \\
\hline
\end{tabular}

Sumber:Hasil Pengolahan Data , 2015

\section{Biaya Variabel (Variabel Cost)}

Biaya variabel adalah biaya yang memiliki hubungan erat dengan tinggi rendahnya hasil produksi yang diperoleh. Biaya yang termasuk biaya variabel dalam usaha penggilingan padi adalah biaya bahan bakar, upah operator, spidol dan biaya pemeliharaan atau perbaikan. Data biaya variabel dapat dilihat pada tabel 6 .

Tabel 6.

Biaya Variabel

\begin{tabular}{|c|c|c|c|c|c|c|}
\hline \multirow[b]{2}{*}{ No } & \multirow[b]{2}{*}{ Tahun } & \multicolumn{4}{|c|}{ Uraian } & \multirow[b]{2}{*}{ Jumlah } \\
\hline & & Bahan Bakar & $\begin{array}{c}\text { Upah } \\
\text { Operator }\end{array}$ & Spidol & $\begin{array}{c}\text { Biaya } \\
\text { Pemeliharaan }\end{array}$ & \\
\hline 1 & 2010 & $8,960,000$ & $4,400,000$ & 120,000 & $3,990,000$ & $27,470,000$ \\
\hline 2 & 2011 & $8,001,000$ & $18,000,045$ & 120,000 & $4,160,000$ & $30,281,045$ \\
\hline 3 & 2012 & $9,800,000$ & $31,500,000$ & 144,000 & $4,950,000$ & $46,394,000$ \\
\hline 4 & 2013 & $12,240,000$ & $30,600,000$ & 156,000 & $5,053,000$ & $48,049,000$ \\
\hline 5 & 2014 & $11,304,000$ & $38,160,000$ & 168,000 & $5,645,000$ & $55,277,000$ \\
\hline \multicolumn{2}{|c|}{ Jumlah } & $50,305,000$ & $132,660,045$ & 708,000 & $23,798,000$ & $207,471,045$ \\
\hline \multicolumn{2}{|c|}{ Rata-Rata } & $10,061,000$ & $26,532,009$ & 141,600 & $4,759,600$ & $41,494,209$ \\
\hline
\end{tabular}

Sumber: Hasil Pengolahan Data , 2015

\section{Biaya Total (Biaya Cost)}

Biaya total (TC) merupakan penjumlahan antara total biaya tetap dengan total biaya variabel. Untuk lebih rinci dapat dilihat pada tabel 7 .

Tabel 7.

Biaya Operasional

\begin{tabular}{|c|c|c|c|c|}
\hline \multirow[b]{2}{*}{$\mathrm{NO}$} & \multicolumn{4}{|c|}{ Uraian } \\
\hline & Tahun & $\begin{array}{c}\text { BiayaTetap } \\
\text { (Rp) }\end{array}$ & $\begin{array}{c}\text { BiayaVariab } \\
\text { el (Rp) }\end{array}$ & TOTAL \\
\hline 1 & 2010 & 3.846 .100 & 27.470 .000 & 31.316 .100 \\
\hline 2 & 2011 & 3.846 .100 & 30.281 .045 & 34.127 .145 \\
\hline 3 & 2012 & 3.846 .100 & 46.394 .000 & 50.240 .100 \\
\hline 4 & 2013 & 3.846 .100 & 48.049 .000 & 51.895 .100 \\
\hline 5 & 2014 & 3.846 .100 & 55.277 .000 & 59.123 .100 \\
\hline \multicolumn{2}{|c|}{ Jumlah } & 19.230 .500 & 207.471 .045 & 226.701 .545 \\
\hline \multicolumn{2}{|c|}{ Rata-Rata } & 3.846 .100 & 41.494 .209 & 45.340 .309 \\
\hline
\end{tabular}

Sumber: Data diolah, 2015 


\section{Penerimaan}

Penerimaan merupakan hasil kali dari hasil produksi dengan $\mathrm{Harga} / \mathrm{Kg}$. Data mengenai penerimaan usaha penggilingan padi "Sumber Hidup" di Desa Marindi Kecamatan Haruai dapat dilihat pada tabel 8.

Tabel 8.

Hasil Produksi

\begin{tabular}{cccc}
\hline Tahun & $\begin{array}{c}\text { Hasil } \\
\text { Produksi } \\
(\mathrm{Kg})\end{array}$ & Harga/Kg & $\begin{array}{c}\text { Penerimaan } \\
(\mathrm{Rp})\end{array}$ \\
\hline 2010 & 192.000 & 250 & 48.000 .000 \\
2011 & 171.429 & 350 & 60.000 .150 \\
2012 & 210.000 & 500 & 105.000 .000 \\
2013 & 204.000 & 500 & 102.000 .000 \\
2014 & 212.000 & 600 & 127.200 .000 \\
\hline Jumlah & 989.429 & 2.200 & 442.200 .150 \\
Rata-rata & 197.885 .71 & 440 & 88.440 .030 \\
\hline
\end{tabular}

Keuntungan

Keuntungan usaha penggilingan padi "Sumber Hidup" di Desa Marindi Kecamatan
Haruai Kabupaten Tabalong dapat dilihat pada tabel 9 (lampiran)

Tabel 9.

Keuntungan Usaha

\begin{tabular}{cccr}
\hline Tahun & $\begin{array}{c}\text { Penerimaan } \\
(\mathrm{Rp})\end{array}$ & $\begin{array}{c}\text { Biaya } \\
\text { Operasional } \\
(\mathrm{Rp})\end{array}$ & $\begin{array}{c}\text { Keuntungan } \\
(\mathrm{Rp})\end{array}$ \\
\hline 2010 & 48.000 .000 & 31.316 .100 & 16.683 .900 \\
2011 & 60.000 .150 & 34.127 .145 & 25.873 .005 \\
2012 & 105.000 .000 & 50.240 .100 & 54.759 .900 \\
2013 & 102.000 .000 & 51.895 .100 & 50.104 .900 \\
2014 & 127.200 .000 & 59.123 .100 & 68.076 .900 \\
\hline Jumlah & 442.200 .150 & 226.701 .545 & 215.498 .605 \\
Rata-rata & 88.440 .030 & 45.340 .309 & 43.099 .721 \\
\hline Sumber:
\end{tabular}

Sumber: Hasil Pengolahan , 2015

\section{Analisis Kelayakan Usaha}

Kelayakan usaha ini dapat dihitung dengan menggunakan beberapa kriteria penilaian investasi, yaitu Net Present Value (NPV),

Net Present Value (NPV) adalah nilai sekarang dari selisih antara benefit (manfaat) dengan cost (biaya) pada discount rate tertentu.
Internal Rate of Return (IRR), Net Benefit Cost Ratio (Net B/C) dan sensitivitas

\section{Net Present Value (NPV)}

Untuk perhitungan Net Present Value (NPV) pada usaha penggilingan "Sumber Hidup" dapat dilihat pada tabel 10 . 
Gusti Marliani, Evaluasi Usaha Penggilingan Padi......

Tabel 10.

Persiapan Perhitungan Analisis Kelayakan Investasi NPV

\begin{tabular}{ccccccc}
\hline NO & Tahun & Cost & Benefit & Net Benefit & $\begin{array}{c}\text { DF } \\
\mathbf{1 8 \%}\end{array}$ & $\begin{array}{c}\text { Present } \\
\text { Value }\end{array}$ \\
\hline 1 & 0 & 53.720 .000 & - & $(53.720 .000)$ & 1,000 & $(53.720 .000)$ \\
2 & 1 & 31.316 .100 & 48.000 .000 & 16.683 .900 & 0,847 & 14.131 .263 \\
3 & 2 & 34.127 .145 & 60.000 .150 & 25.873 .005 & 0,178 & 4.605 .395 \\
4 & 3 & 50.240 .100 & 105.000 .000 & 54.759 .900 & 0,609 & 33.348 .779 \\
5 & 4 & 51.895 .100 & 102.000 .000 & 50.104 .900 & 0,516 & 25.854 .128 \\
6 & 5 & 59.123 .100 & 127.200 .000 & 68.076 .900 & 0,437 & 29.749 .605 \\
\hline \multicolumn{7}{c}{ NPV 1 } \\
\hline
\end{tabular}

Sumber: Hasil Pengolahan Data Primer, 2015

Internal Rate of Return (IRR)

Internal Rate of Return (IRR) adalah suatu tingkat discoutn rate yang menghasilkan $\mathrm{NPV}=0$ (nol). Jika IRR > SOCC maka usaha tersebut dikatakan layak. Untuk menghitung nilai IRR harus dihitung terlebih dahulu nilai NVP1dan NVP2 dengan coba-coba. Untuk perhitungan Net Present Value (NPV) pada usaha penggilingan padi "Sumber Hidup" dapat dilihat pada tabel 11 (lampiran).

Sehingga perhitungan hasil IRR sebagai berikut:

$$
\operatorname{IRR}=18 \%+\frac{53.969 .171}{53.969 .171-(7.901 .381)}(30 \%-18 \%)
$$

$\operatorname{IRR}=0,18+\frac{53.969 .171}{53.969 .171-(7.901 .381)}(12 \%)$

$\operatorname{IRR}=0,18+\frac{6.476 .301}{61.870 .552}$

$\operatorname{IRR}=0,18+0,1047$

$\operatorname{IRR}=0,2847=28,47 \%$

Jadi nilai dari IRR adalah $28,47 \%$

\section{Net Benefit Cost Ratio (Net B/C )}

Net Benefit Cost Ratio (Net B/C) merupakan nilai manfaat yang bisa didapatkan dari proyek atau usaha setiap kita mengeluarkan biaya sebesar satu rupiah untuk proyek atau usaha tersebut. Net B/C merupakan perbandingan antara NPV positif dengan NPV negatif. Nilai Net B/C memiliki arti yaitu Net $\mathrm{B} / \mathrm{C}>1$, maka berarti proyek atau usaha layak dijalankan secara Finansial Net $\mathrm{B} / \mathrm{C}=1$, hal ini juga berarti bahwa usaha atau proyek tersebut berada dalam keadaan break even point. Net $\mathrm{B} / \mathrm{C}<1$, maka berarti proyek atau usaha tidak layak dijalankan secara finansial. Untuk perhitungan Net Benefit Cost Ratio (Net B/C) pada usaha penggilingan padi "Sumber Hidup" dapat dilihat pada tabel 11 .

Berdasarkan tabel tersebut, maka perhitungan Net B/C, sebagai berikut: $=\frac{14.131 .263+4.605 .395+33.348 .779+25.854 .128+29.749 .605}{53.720 .000}$

$=\frac{107.689 .170}{53.720 .000}$

Net $B / C=2,00$

Jadi nilai Net $\mathrm{B} / \mathrm{C}$ pada usaha penggilingan padi Sumber Hidup adalah 2,005

\section{Sensitivitas Kelayakan Usaha Penggilingan Padi "Sumber Hidup"}

Analisis sensitivitas dilakukan untuk mempelajari kemungkinan terjadinya perubahan pada salah satu komponen biaya. 
Untuk studi dalam penelitian ini komponen biaya yang digunakan untuk perhitungan analisis sensitivitas adalah biaya operasional 10\% sampaidengan 50\% terhadap NPV, IRR dan Net B/C. Hasil perhitungan analisis sensitivitas kenaikan biaya operasional dapat dilihat pada tabel 12 .

Tabel 12

Analisis Sensitivitas Terhadap Kenaikan Biaya Operasional

\begin{tabular}{cccc}
\hline $\begin{array}{c}\text { Kenaikan } \\
\text { Biaya } \\
\text { Operasional } \\
\text { \% }\end{array}$ & NPV & IRR & Net B/C \\
\hline 10 & 42.388 .145 & $27,13 \%$ & 1,79 \\
20 & 30.807 .120 & $25,46 \%$ & 1,57 \\
30 & 19.672 .038 & $23,32 \%$ & 1,36 \\
40 & 8.125 .317 & $20,46 \%$ & 1,14 \\
50 & -3.421 .403 & $16,48 \%$ & 0,93 \\
\hline
\end{tabular}

Sumber: Hasil Pengolahan Data Primer, 2015

\section{PEMBAHASAN}

\section{Analisis Biaya dan Pendapatan Produksi}

Komponen biaya yang dihitung dan dianalisis pada usaha penggilingan padi meliputi biaya tetap (Fixed Cost) dan biaya variabel (Variabel Cost). Biaya tetap dalam usaha penggilingan padi "Sumber Hidup" di Desa Marindi Kecamatan Haruai Kabupaten Tabalong meliputi biaya Pajak Bumi Bangunan (PBB) dan penyusutan alat. Sedangkan biaya variabel meliputi biaya bahan bakar dan upah tenaga kerja, alat tulis dan Biaya pemeliharaan atau perbaikan.

\section{Biaya Tetap (Fixed Cost)}

Biaya Penyusutan Alat

Perhitungan nilai penyusutan alat perlengkapan berdasarkan metode garis lurus yakni nilai awal di kurangnilaisisa dibagi usia ekonomis alat.

Biaya penyusutan pada bangunan untuk penggilingan padi sebesar Rp 1.350.000,- biaya penyusutan pada mesin pemecah gabah dan mesin penyosoh sebesar Rp 950.000,- biaya penyusutan pada tong 1200 lt sebesar Rp 114.000 ,- biaya penyusutan pada alat timbangan sebesar Rp 142.500,- biaya penyusutan pada bakul sebesar Rp 225.000,biaya penyusutan pada drum sebesar $\mathrm{Rp}$ 72.000,- biaya penyusutan pada derigen sebesar Rp 18.000,- biaya penyusutan pada belik sebesar Rp 9.000,- biaya penyusutan pada literan sebesar Rp 3.600,-. Jadi biaya penyusutan alat perlengkapan keseluruhan usaha penggilingan padi adalah sebesar $\mathrm{Rp}$ 3.834.100,-

Secara keseluruhan biaya tetap yang dikeluarkan oleh pengusaha penggilingan padi "Sumber Hidup" adalah sebesar Rp 3.846.100,/tahun. Biaya tetap untuk pajak bumi dan bangunan 12.000,-/tahun dan biaya penyusutan sebesar Rp 3.834.100,-/tahun. Biaya Pajak Bumi Bangunan (PBB)

Biaya pajak bumi bangunan ini merupakan iuran tetap yang diwajibkan kepada pemilik usaha untuk dibayarkan kepada pemerintahan daerah setempat, besarnya biaya PBB ini mengikuti ketentuan yang berlaku di Kabupaten Tabalong dimana biaya PBB setiap tahunnya adalah Rp. 12.000,-.

\section{Biaya variabel (Variabel Cost)}

Biaya yang termasuk biaya variabel dalam usaha penggilingan padi adalah biaya bahan bakar, upah operator, alat tulis dan biaya pemeliharaan. Data biaya variabel usaha penggilinagn padi "Sumber Hidup" dapat dilihat pada tabel 6 .

Berdasarkan hasil analisis dan pengolahan data primer pada tabel 6 , maka total biaya variabel untuk usaha penggilingan padi "Sumber Hidup" sebesar Rp 207.471.045,dengan rata-rata Rp 41.494.209,-/tahun. Biaya variabel terdiri dari biaya bahan bakar sebesar Rp 50.305.00,- biaya upah operator Rp.132.660.045,- biayaalattulis Rp.708.000,dan biaya pemeliharaan atau perawatan Rp. 23.798.000,--

\section{Biaya Total (Total Cost)}

Biaya total (TC)/biaya operasional merupakan penjumlahan antara total biaya tetap dengan total biaya variabel. Berdasarkan dari hasil perhitungan tabel 7 , maka biaya total keseluruhan yang dikeluarkan untuk usaha 
penggilingan padi "Sumber Hidup' di Desa Marindi Kecamatan Haruai Kabupaten Tabalong adalah sebesar Rp 226.701.545,-.

\section{Biaya Total (Total Cost)}

Biaya total (TC)/biaya operasional merupakan penjumlahan antara total biaya tetap dengan total biaya variabel. Berdasarkan dari hasil perhitungan tabel 7 , maka biaya total keseluruhan yang dikeluarkan untuk usaha penggilingan padi "Sumber Hidup' di Desa Marindi Kecamatan Haruai Kabupaten Tabalong adalah sebesar Rp 226.701.545,-.

\section{Keuntungan}

Keuntungan merupakan selisih antara penerimaan total dengan biaya-biayadimana biaya tersebut adalah biaya tetap dan biaya tidak tetap. Keuntungan usaha penggilingan padi "Sumber Hidup" di DesaMarindidapat dilihat pada tabel 10. Berdasarkan hasil dari analisis dan data primer, maka dapat diketahui besarnya keuntungan yang diperoleh oleh usaha penggilingan padi "Sumber Hidup" selama 5 tahun sebesar Rp 215.498.605,- dan dengan rata-rata setiap tahunnya sebesar $\mathrm{Rp}$ 43.099.721,-/tahun.

\section{Kelayakan Usaha}

Kelayakan usaha adalah kelayakan tentang layak tidaknya suatu usaha penggilingan padi "Sumber Hidup" yang dilaksanakan di Desa Marindi Kecamatan Haruai Kabupaten Tabalong dengan membandingkan penerimaan dengan keseluruhan biaya. Kelayakan usaha ini dapat dihitung dengan menggunakan beberapa kriteria penelitian investasi, yaitu Net Present Value (NPV), Internal Rate of Return (IRR), Net Benefit Cost Ratio (Net B/C ) dan sensivitas usaha.

\section{Net Present Value (NPV)}

Net Present Value (NPV) adalah nilai sekarang dari selisih antara benefit (manfaat) dengan cost (biaya) pada discount rate tertentu. Berdasarkan dari hasil perhitungan pada tabel 10 diatas, dapat diperoleh Net Present Value (NPV) sebesar Rp 53.969.171,- dengan menggunakan tingkat suku bunga sebesar $18 \%$.
Hasil penelitian ini menunjukkan bahwa NPV $>0$, yang berarti usaha penggilingan padi "Sumber Hidup" di Desa Marindi layak untuk diusahakan.

\section{Internal Rate of Return (IRR)}

IRR adalah suatu tingkat discount rate yang menghasilkan NPV $=0$ (nol). Jika IRR > SOCC maka usaha tersebut dikatakan layak. Untuk menghitung nilai IRR harus dihitung terlebih dahulu nilai NPV1 dan NPV2 dengan cara coba-coba. IRR pada Usaha Penggilingan Padi "Sumber Hidup" di Desa Marindi Kecamatan Haruai dapat dilihat pada tabel 11. Dari hasil percobaan ini, nilai IRR berada antara nilai NPV positif dan nilai NPV negatif yaitu NPV sama dengan nol $(\mathrm{NPV}=0)$, maka hasil perhitungan tersebut menunjukkan IRR sebesar 28,47\% dan Social Opportunity Cost of Capital (SOCC) sebesar 18\%, ini berarti IRR > SOCC, dengan demikian usaha penggilingan padi "Sumber Hidup" di Desa Marindi Kecamatan Haruai Kabupaten Tabalong layak untuk diusahakan.

\section{Net Benefit Cost Ratio (Net B/C)}

Net B/C adalah perbandingan antara net benefit yang telah didiskon positif dengan net benefit yang telah didiskon negatif. Untuk perhitungan Net Benefit Cost Ratio(Net $\mathrm{B} / \mathrm{C}$ )pada usaha penggilingan padi "SumberHidup" dapat dilihat pada tabel 11.

Dari hasil perhitungan pada tabel 10 diatas, dapat diperoleh $\mathrm{Net} B / \mathrm{C}$ sebesar 2,00. Hasil penelitian ini menunjukkan bahwa Net $\mathrm{B} / \mathrm{C}>1$, yang berarti usaha penggilingan padi "Sumber Hidup" di Desa Marindi layak untuk diusahakan.

\section{Sensitivitas Kelayakan}

Analisis sensitivitas dilakukan untuk mempelajari kemungkinan terjadinya perubahan pada salah satu komponen biaya. Untuk studi dalam penelitian ini komponen biaya yang digunakan untuk perhitungan analisis sensitivitas terhadap biaya operasional $10 \%, 20 \%, 30 \%, 40 \%$ dan $50 \%$ dengan NPV, IRR dan Net B/C. Hasil perhitungan analisis sensitivitas kenaikan biaya operasional dapat dilihat pada tabel 12 . 
Berdasarkan tabel 12, dapat diketahui analisis sensitivitas terhadap kenaikan biaya operasional sebesar 10\%, maka nilai NPV sebesar Rp 42.388.145,- nilai IRR sebesar 27,13\%,dan Net B/C sebesar 1,79. Pada analisis sensitivitas terhadap kenaikan biaya operasional sebesar 20\%, maka nilai NPV sebesar Rp 30.807.120,- nilai IRR sebesar 25,46\%, dan Net B/C sebesar 1,57. Pada analisis sensitivitas terhadap kenaikan biaya operasioanal sebesar 30\%, maka nilai NPV sebesar Rp19.226.094,-, nilai IRR sebesar 23,32\%, dan nilai Net B/C sebesar 1,36. Pada analisis sensitivitas terhadap kenaikan biaya operasioanal sebesar $40 \%$, maka nilai NPV sebesar Rp7.645.069,-, nilai IRR sebesar 20,46\%, dan nilai Net B/C 1,14 untuk lebih jelasnya dapat dilihat pada lampiran 12.Sedangkan analisis sensitivitas terhadap kenaikan biaya operasional sebesar 50\%, maka nilai NPV sebesar Rp -3.935.957,-, nilai IRR sebesar $16.48 \%$, dan Net B/C sebesar 0,93.

\section{SIMPULAN}

Analisis kelayakan usaha menunjukkan bahwa usaha penggilingan padi "Sumber Hidup" di Desa Marindi Kecamatan Haruai Kabupaten Tabalong layak untuk diusahakan, adapun hasil analisis sensitivitas daapt diketahui bahwa usaha ini masih dikatakan layak namun apabila kenaikan operasionalnya mencapai $50 \%$ dari harga normal maka membuat usaha penggilingan padi tidak layak untuk diusahakan.

\section{SARAN}

Penelitian yang telah dilakukan pada usaha penggilingan padi "Sumber Hidup" di Desa Marindi Kecamatan Haruai Kabupaten Tabalong, sudah dikatakan layak, tetapi perlu diperhatikan masalah administrasi atau keuangannya, selain itu untuk menambah nilai dari pendapatan hendaknya pemilik usaha penggilingan padi memanfaatkan hasil limbah (sekam) untuk dijadikan abu gosok, Briket arang sekam dan lain-lain.

\section{DAFTAR PUSTAKA}

BPP Kecamatan Kembang Kuning. 2014 Laporan Tahunan.Tanjung. Tabalong.

Choliq, Abdul. Wirasasmita H. R. A. Rivai dan Hasan, Sumarna 1999. Evaluasi Proyek (Suatu Pengantar). Pionir Jaya. Bandung Ibrahim, Y. 2009. Studi Kelayakan Bisnis. Rineka Cipta Jakarta.

Idris, 2013. Analisis Kelayakan Usaha Penggilingan Padi "Tiga Bersaudara". Di Desa Bungin Kecamatan Paringin Selatan Kabupaten Balangan. Skripsi. STIPER. Amuntai.

Kasmir dan Jakfar, 2003. Studi Kelayakan Bisnis. Kencana, Jakarta

Peraturan Menteri Pertanian Nomor 44/Permentan/OT.140/10/2009. 2009.

Pedoman Penanganan Pascapanen Hasil Pertanian Asal Tanaman yang Baik (God Hardling Practices). Jakarta.

Pradhana, A. Y. 2011. Analisis Biaya dan Kelayakan Usaha Penggilingan Padi DI Desa Cihideung Ilir Kecamatan Ciampea Kabupaten Bogor. Skripsi. IPB Bogor.

Wulan Sapmaya, 2010. Studi Kelayakan Usaha Pencucian Mobil Otomatis pada Perusahaan Auto Car Wash di Bandar Lampung, Jurnal Manajemen dan Bisnis Vol 1.No.1 Oktober $2010: 21-32$. 